\title{
Poly(Butylene Terephthalate) Based Composites Containing Alumina Whiskers: Influence of Filler Functionalization on Dielectric Properties
}

\author{
Pietro Russo, ${ }^{1}$ Francesca Cimino, ${ }^{2}$ Domenico Acierno, ${ }^{3}$ \\ Giovanni Lupò, ${ }^{4}$ and Carlo Petrarca ${ }^{4}$ \\ ${ }^{1}$ Institute of Polymers, Composites and Biomaterials, National Council of Research of Italy, Via Campi Flegrei, \\ 34-80072 Pozzuoli, Italy \\ ${ }^{2}$ Department of Chemical, Materials Engineering and Industrial Production, University of Naples Federico II, \\ Piazzale Tecchio, 80-80125 Naples, Italy \\ ${ }^{3}$ INSTM-Reference Centre for Processing Technology of Polymers and Composites, University of Naples Federico II, \\ Piazzale Tecchio, 80-80125 Naples, Italy \\ ${ }^{4}$ Department of Electrical Engineering and Information Technology, University of Naples Federico II, Piazzale Tecchio, \\ 80-80125 Naples, Italy
}

Correspondence should be addressed to Pietro Russo; pietro.russo@unina.it

Received 22 July 2013; Accepted 7 March 2014; Published 2 April 2014

Academic Editor: Nanda Gopal Sahoo

Copyright (C) 2014 Pietro Russo et al. This is an open access article distributed under the Creative Commons Attribution License, which permits unrestricted use, distribution, and reproduction in any medium, provided the original work is properly cited.

Poly(butylene terephthalate) (PBT) is one of the most widely used semicrystalline thermoplastics polyester because of its superior thermal and mechanical properties, high dimensional stability and excellent processability. In this research PBTbased nanocomposites, including various amounts (up to $10 \mathrm{wt} \%$ ) of commercial alumina whiskers, have been prepared by using a Brabender internal chamber mixer and analysed in terms of morphological features and dielectric properties. Specific attention has been focused on the effect of the filler functionalization considering 3-glycidoxy propylmethoxysilane (GPS) or 3methacryloxypropyltrimethoxysilane (MPS) as coupling agents. Tests, performed on compounds filled with neat and functionalized alumina whiskers, show a clear dependence of relative dielectric permittivity $\left(\varepsilon_{r}\right)$, invariance of dissipation factor $(\operatorname{tg} \delta)$, and a sensible increase of volume electrical resistivity $\left(\rho_{v}\right)$ with the filler's content and are encouraging for a future introduction of such composites in many electrical applications.

\section{Introduction}

Poly(butylene terephthalate) (PBT) resins are semicrystalline thermoplastics with very interesting properties such as excellent dimensional stability, high stiffness and hardness, good resistance to chemicals, good mechanical properties, and processability. Consequently they are used in a wide variety of applications to obtain items mainly obtained by injection molding.

However, the ever increasing use of plastics in place of traditional materials has fed an increasing demand to develop higher performance PBT resins suitable for various processing conditions and, thus, to be utilized in various advanced fields by blending with other resins [1-5] or compounding with inorganic fillers [6-11]. In this latter case, with the awareness that optimal combinations of organic (polymer) and inorganic (nanofiller) phases can lead to novel functional materials, if an optimal distribution of the filler is achieved, interesting results are already reported in terms of improvements of several performances as UV resistance [12, 13] and flammability [14-17] of poly(butylene) terephthalate resins.

Nowadays, the continuous tendency towards the miniaturization of components, the introduction of more severe duty cycles, the reduction in maintenance costs [18], or new technologies $[19,20]$ guides the research to investigate 
novel dielectric materials which would enable achieving higher electrical, mechanical, and thermal performances for electric and electronic applications. At this regard, it is known that ceramics have high dielectric permittivity and significant dielectric strength and high thermal shock resistance and chemical stability against acid-alkali corrosion but they are brittle and have poor mechanical strength. Vice versa, polymers are flexible and easy to process, have low dielectric permittivity, and can withstand high fields. So the idea is to combine the advantages of polymers and ceramics to obtain new hybrid materials with improved dielectric characteristics for several applications as in capacitors, in electrical machines, in cables, and so forth. In particular, with the advent of nanotechnology and the availability of nanosized fillers (having at least one dimension less than $100 \mathrm{~nm}$ ), the research for "new" materials has focused its efforts on studying polymer composites obtained by adding to the original matrix various nanofillers of different shape, dimension, and weight percentage in order to impart one or more specific properties to the insulation system.

In this frame, several results of the research have been already reported on epoxy based nanodielectric systems [21-26], silicone nanocomposites [27, 28] but also regarding composite systems based on thermoplastic matrices as polyethylene [29, 30], ethylene-vinyl alcohol (EVA) [31, 32], and poly(vinylidene fluoride) (PVDF) [33-35].

In general, it is well established that the nature of the interfacial region plays a key role in determining the dielectric behavior of these materials. Interaction and enhanced area of the interface by inclusion of nanofillers affect the interfacial polarization through the formation of local conductivity [22]. Increases of permittivity of nanocomposites are mainly attributed to the higher permittivity of fillers with respect to the matrix, while decreases of the same dielectric parameter are usually related to restrictions of polymer chain movements at the interfaces.

At this regard, it is worth to consider that in a dielectric material differences between the rate of charge accumulation and the rate of charge removal upon the application of an electrical field induce space charge phenomena which cause local increases of the internal field. Taking into account that this behavior can lead to faster degradation and premature failure of the materials, a specific attention is paid on the mechanisms of space charge formation related to the overall dielectric behavior of polymer materials $[36,37]$. The research on composites has demonstrated that nanosized particles reduce the charge accumulation with dynamics much faster than in systems containing microsized ones [38] and that nanocomposites usually exhibit lowered and redistributed space charge when compared with microcomposites [39]. This behavior, according to Montanari et al. [40], can be explained assuming that, in presence of nanoparticles, shallow trap bands are formed, which either distribute or replace the original trap band, especially at high filler loadings. The presence of shallow trap bands results in higher mobility of charge carriers and hence in lower space charge accumulation. However, in certain nanocomposites it is also reported that the presence of deep traps [41], instead, would worsen the same accumulation of charges. Given that the space charge behavior is affected by the nature of both filler and matrix and by the properties of the interface, it is clear that also in this case a better understanding of the dielectric properties of polymer composite materials goes through the analysis of filler-matrix interactions.

Main aim of the research was to investigate the effect of relatively low contents of $\mathrm{Al}_{2} \mathrm{O}_{3}$ whisker-type nanoparticles on the dielectric properties of polybutylene terephthalate based nanocomposites prepared by batch melt compounding. In light of the above observations, in this work two different chemical pretreatments of alumina whisker particles were used to improve interactions at the interface with the host matrix. The actual yield of chemical modifications based on 3-glycidoxy propylmethoxysilane (GPS) or 3-(methacryloxypropyl)trimethoxysilane (MPS) performed according to routes reported elsewhere $[42,43]$ was systematically verified by IR spectroscopic investigations.

In all cases, after having verified the achievement of a satisfactory dispersion of the filler in the host PBT matrix by morphological observations, effects related to filler content and type of applied particle functionalization on dielectric parameters of products such as volume resistivity, permittivity, and dissipation factor evaluated at room temperature have been reported and discussed invoking the previous mentioned approaches.

\section{Materials and Methods}

2.1. Materials. The polymeric matrix used in this study was the poly(butylene terephthalate) (PBT) POCAN B1505 (MFI $250^{\circ} \mathrm{C} / 2.16 \mathrm{~kg}: 16 \mathrm{~g} / 10 \mathrm{~min}, \rho: 1.31 \mathrm{~g} / \mathrm{cm}^{3}, T_{m}: 225^{\circ} \mathrm{C}$ ) supplied by Lanxess $\mathrm{GmbH}$.

Commercial alumina whiskers $\left(\mathrm{Al}_{2} \mathrm{O}_{3}\right)$, provided by Sigma-Aldrich with particle diameter $2-6 \mathrm{~nm}$ and length 200-400 nm, were used as fillers.

3-glycidoxy propylmethoxysilane (GPS) and 3-(methacryloxypropyl)trimethoxysilane (MPS) purchased from Sigma-Aldrich Chemical Company were employed to pretreat alumina whiskers.

2.2. Preparation of $\mathrm{PBT} / \mathrm{Al}_{2} \mathrm{O}_{3}$ Whisker Nanocomposites. The nanocomposites were prepared in laboratory scale in successive phases according to the following procedure. The inclusion of $1 \%, 3 \%, 5 \%, 7 \%$, and $10 \%$ by weight of nanosized particles of as received or prefunctionalized alumina whiskers in the molten PBT was carried out by the batch mixing technology. In particular, all composite systems were prepared in a Brabender-type internal mixer (Rheocord EC della HAAKE, NJ) at $235^{\circ} \mathrm{C}$ for a total mixing time of $10 \mathrm{~min}$. The rotor speed was $80 \mathrm{rpm}$. The application of a centrifugal force produces a turbulent movement of the melt in which the high shear forces tend to separate the nanoparticles in order to avoid the formation of aggregates. Before compounding, PBT and alumina nanoparticles were dried overnight in a vacuum oven at $90^{\circ} \mathrm{C}$. Plane, disc-shaped samples for dielectric measurements, characterized by a thickness ranging between 0.9 and $1.0 \mathrm{~mm}$ and diameter $d=8 \mathrm{~cm}$, were obtained by using a lab hydraulic press operating at $240^{\circ} \mathrm{C}$ and 70 bar. 


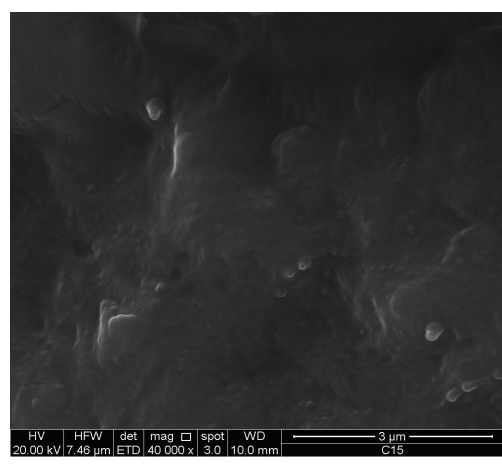

(a)

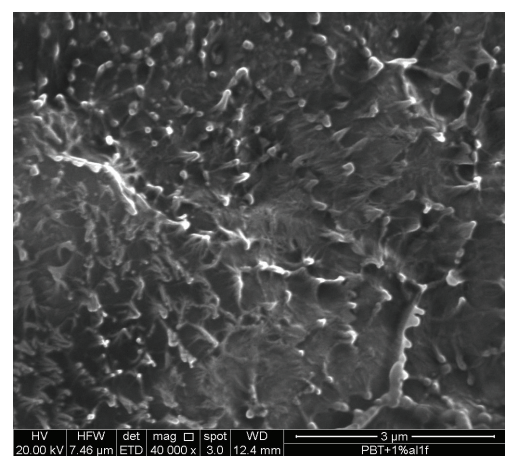

(b)

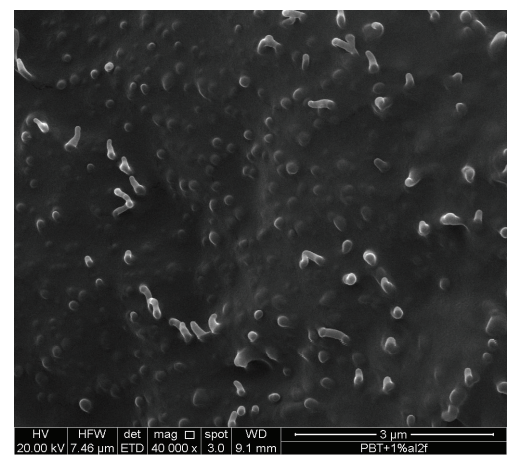

(c)

FIGURE 1: SEM micrographs of fracture surfaces of samples containing $1 \%$ by weight of alumina whiskers as received (a), functionalized with GPS (b), and functionalized with MPS (c).

2.3. Characterization Techniques. Microscopic analysis was performed by using a field emission scanning electron microscope (SEM) Mod. FEI QUANTA 200F equipped with an energy dispersion spectrometer (EDS) Oxford INCA Energy System for element analysis of fractured surfaces. Micrographs have been obtained operating at high vacuum condition on $\mathrm{Cr}$-metalized samples and at $20 \mathrm{kV}$ voltage.

SEM observations were completed by qualitative energy dispersion X-ray spectroscopy (EDS, Oxford, INCA Energy System) analyses in order to confirm the nature of dispersed particles.

DC Volume resistivity $\left(\rho_{v}\right)$ was measured at $21^{\circ} \mathrm{C}$ on the disc-shaped samples. Prior to the measurement, the specimen were held in an oven at the controlled temperature of $30^{\circ} \mathrm{C}$ for 48 hours. Each specimen was held in a suitable shielded cell with guarded ring electrodes and DC voltage of $1400 \mathrm{~V}$, corresponding to an applied electrical field from 14 to $15.5 \mathrm{kV} / \mathrm{cm}$. Readings of the conduction current were taken after $120 \mathrm{~s}$ from the application of the DC voltage, when a stable state was reached.

Permittivity and dissipation factor measurements were performed at room temperature $\left(23^{\circ} \mathrm{C}\right)$ and low voltage $(1.1 \mathrm{~V})$ in the frequency range $(100 \mathrm{~Hz} \div 5 \mathrm{MHz})$ by using an impedance analyzer HP 4192A and a suitable test cell Agilent 16451B. The dielectric test fixture was equipped with a 4 terminal pair cable assembly and was used in the guarded electrode configuration.

\section{Results and Discussion}

3.1. Morphology. All investigated composites were systematically investigated by morphological point of view to verify the actual distribution of the alumina particles within the polymer matrix.

As an example, Figures 1, 2, and 3 compare micrographs, at equal magnification, of systems containing 1, 5, and $10 \%$ by weight of alumina whiskers, respectively. Pictures clearly highlight in all cases the existence of a uniform distribution of dots. Holes which appeared in case of nonfunctionalized samples are probably just related to the expulsion of included particles during the fracture of samples. Instead, expectedly, dots appeared to be linked to the host matrix in case of functionalized systems for which the fracture step induced a certain yielding behaviour of the polyester matrix just in correspondence of alumina particles.

The nature of these dots was verified by an EDS elemental analyses. At this purpose, punctual sampling of the dots gave rise to typical spectra shown in Figure 4 . The analysis of characteristic peaks with the aid of suitable data banks confirmed the attribution of dispersed dots to alumina fillers.

3.2. DC Volume Resistivity. The data presented in the paper are an average value of five samples; three measurements were made for each sample, taking care that between two consecutive measurements the sample was held between grounded electrodes until the short circuit currents fell below the noise level.

Results indicated both an influence of filler functionalization and filler content on DC volume resistivity, as highlighted by the picture shown in Figure 5. The volume resistivity is higher than that in the unfilled resin; in particular, the introduction of a small amount of filler (less than $1 \%$ by weight) increased the DC volume resistivity value $\left(\rho_{v}\right)$ of about 4 orders of magnitude for the functionalized (MPS and GPS) samples and of about 3 orders of magnitude for the nonfunctionalized samples (NOf). When increasing the filler content, resistivity slightly decreases and in the nonfunctionalized samples we find a sudden drop at $10 \%$ alumina content.

With respect to this latter behavior, it is worth to note that, generally, the introduction of inorganic fillers into the matrix can increase the DC conductivity since nanofiller particles, modifying the relaxation of the matrix at the interface, act as ion scavenger which becomes a possible source of ionic carriers to increase the conductivity [44]. The increase in resistivity, instead, may be attributed to the creation of new trap bands, deeper than the original trap band of the base polymer. In fact, the nanoparticle surface creates a change in the polymer structure which can become dominant as the size of filler is reduced and, due to such a structural change, new band can be originated by the surface interaction between the nanofillers and the base polymer, which reduces carrier 


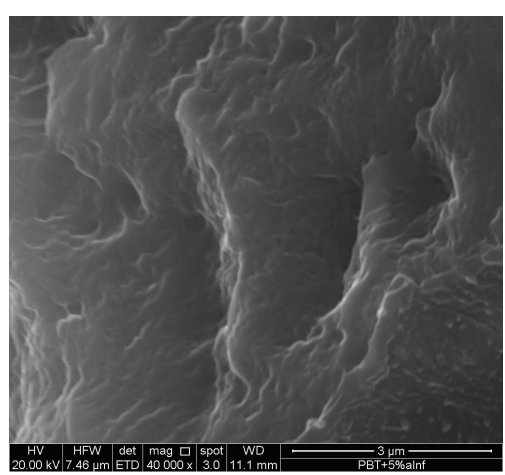

(a)

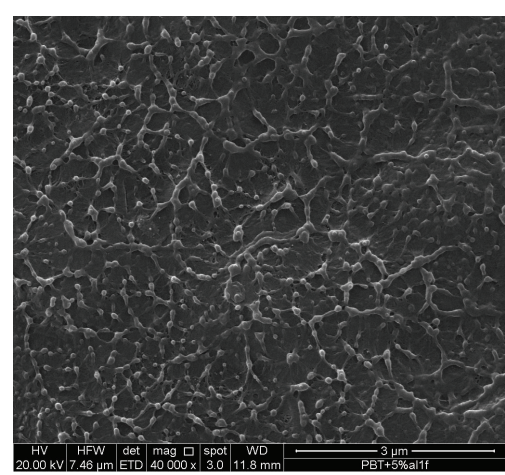

(b)

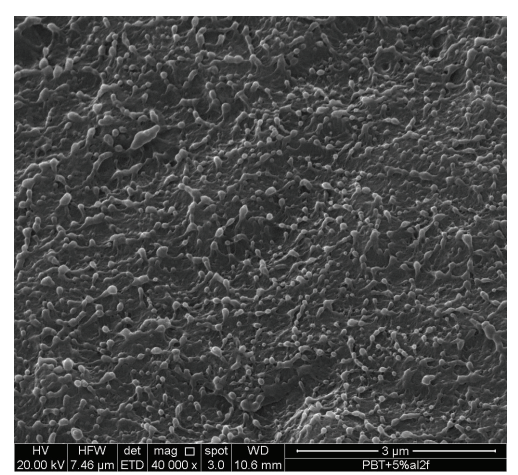

(c)

FIGURE 2: SEM micrographs of fracture surfaces of samples containing $5 \%$ by weight of alumina whiskers as received (a), functionalized with GPS (b), and functionalized with MPS (c).

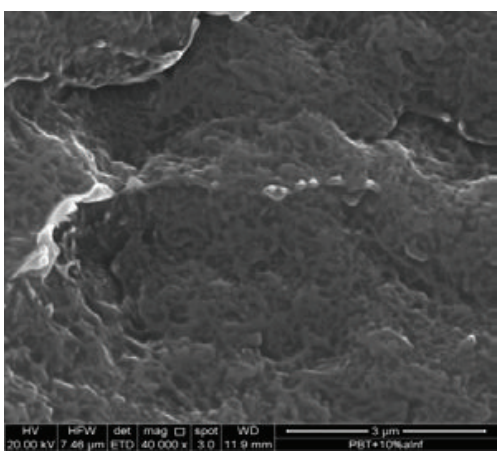

(a)

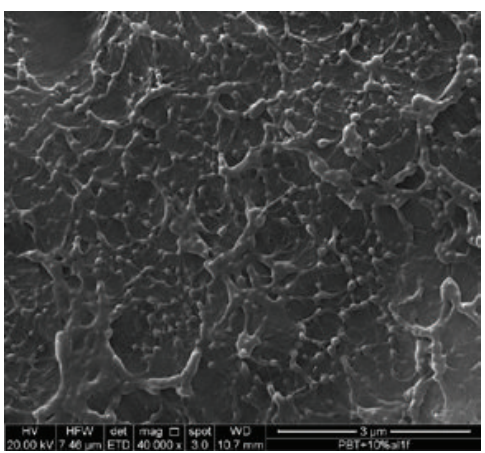

(b)

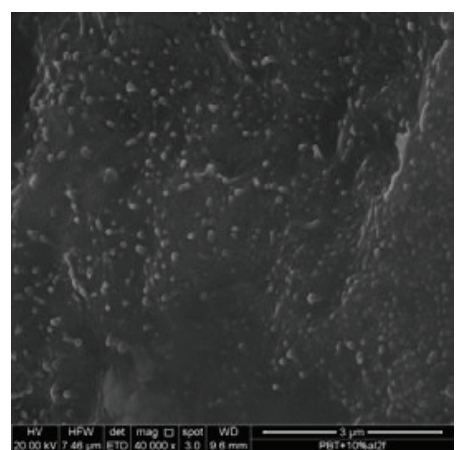

(c)

FIGURE 3: SEM micrographs of fracture surfaces of samples containing $10 \%$ by weight of alumina whiskers as received (a), functionalized with GPS (b), and functionalized with MPS (c).

mobility and increases volume resistivity. The decrease of resistivity with filler content probably indicates that a critical interfacial area has been reached, which corresponds to a minimum of charge carriers mobility and energy and to a strong and stable bonding between the nanofiller surface and the polymer matrix. If the nanocomposite is not functionalized, for high filler contents such an effect disappears and at $10 \%$ filler content the composite is similar to the unfilled material. Experiments are underway to investigate the dielectric behavior in case of nanofiller contents lower than $1 \%$ by weight.

3.3. Dielectric Spectroscopy. Tests were performed using standard equipment and, also in this case, the reported data are mean values of 3 measurements for sample. Each specimen, prior to the measurement, was kept in an oven at a controlled temperature of $30^{\circ} \mathrm{C}$.

We were interested in the real part $\varepsilon^{\prime}$ of complex permittivity $\varepsilon^{*}$ of the material and in the dissipation factor $\operatorname{tg} \delta$ which, respectively, are related to the energy stored in the medium and to losses in the dielectric. Firstly we used the instrumentation to measure the capacitance $C$ and the dissipation factor of each specimen and then the real part of the complex permittivity was obtained by the geometry of the samples.

Regarding the real part of permittivity, this dielectric parameter is generally increased if the base polymer is filled with microsized particles since the filler have higher permittivity than unfilled polymers and cause interfacial polarization phenomena of the Maxwell-Wagner-Sillars type by blocking of charges at the interfaces. On the contrary, in the case of nanosized fillers, as reported in Figure 6, our results showed a slight decrease of relative permittivity $\varepsilon_{r}^{\prime}$ with a filler content up to $3 \% \mathrm{wt}$, a result which is in accordance with many experimental observations [45]. Lower permittivity values can be considered as a sign of a good nanocomposite. This reduction, in line with previous considerations, is probably ascribed to the restriction of polymer chain movement by nanoparticles, due to the modified molecular structure and chain dynamics which cause a strong surface interaction between the filler and the polymer matrix [46]. The multilayered core model proposed by Tanaka [47] takes into account this phenomenon by introducing a tightly bonded first layer between the nanofiller and the polymer matrix. Such bonding leads to restricted mobility of polymer chains and to lower permittivity values.

At higher filler contents, instead, the situation appears to be reversed with the permittivity that becomes greater 


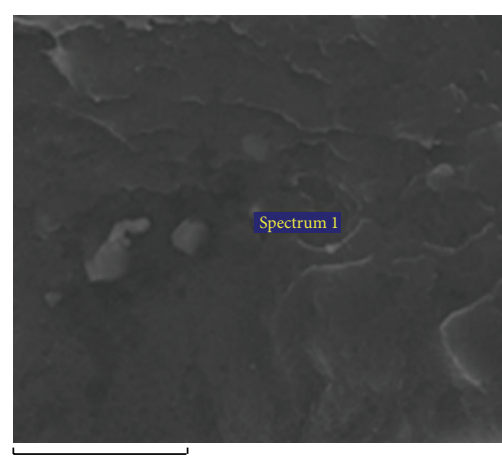

$20 \mu \mathrm{m}$
Electron image 1

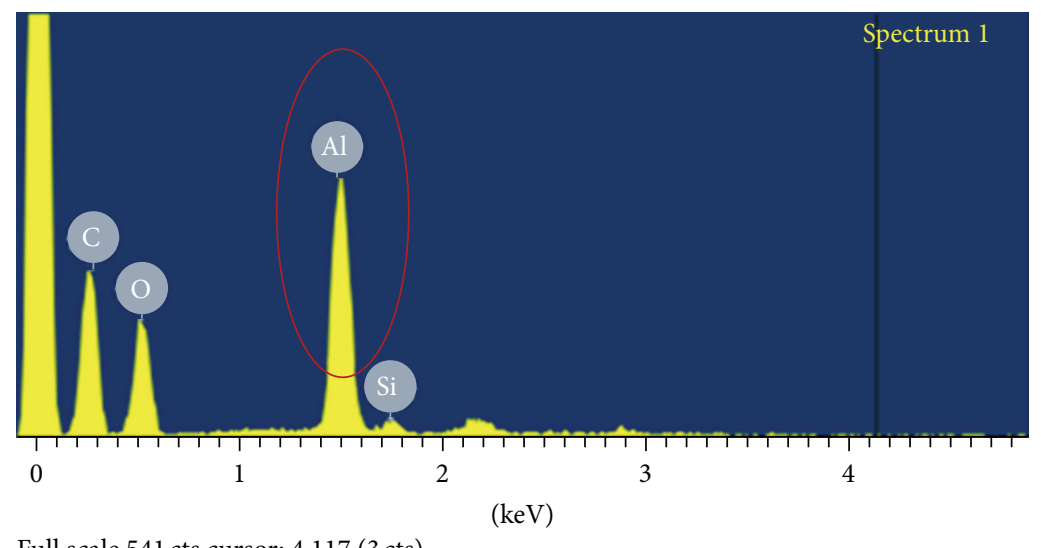

Full scale 541 cts cursor: 4.117 (3cts)

(a)

(b)

FIGURE 4: Elemental EDS analysis of fracture surfaces. Punctual sampling in (a) gives rise to the spectra reported in (b).

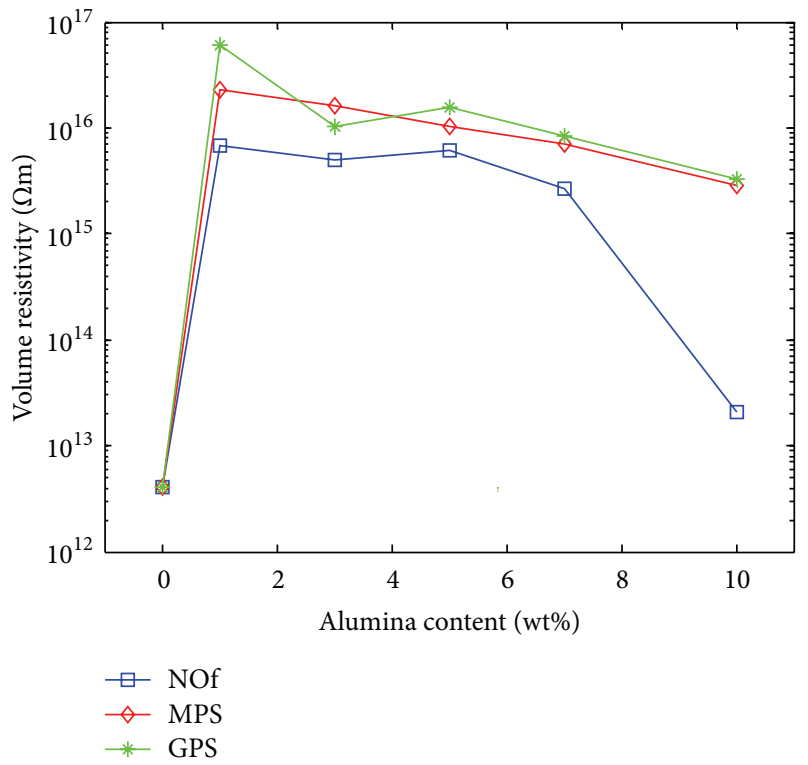

FIGURE 5: Volume resistivity versus alumina content: comparison among nonfunctionalized and functionalized systems.

than the base polymer probably because, in this case, as the volume of filler material increases, the individual permittivity of the nanofillers may give its fundamental contribution. Inhomogeneous dispersion and the formation of clusters can also explain such an increase [48].

As concerns the influence of functionalization on the changes of relative permittivity with respect to the unfilled polymer, it can be observed that the spread between the lower and the maximum value of $\varepsilon_{r}^{\prime}$ is greater in the nonfunctionalized samples, thus confirming that the connection of dipolar groups to the nanoparticle surface can be in this case highly variable, while functionalization makes it much more stronger and stable [49].

In all specimens, the permittivity decreases monotonically with frequency since it becomes more difficult for larger dipolar groups to orient themselves, and their contribution to polarization tends to disappear with frequency.

The frequency response of dissipation factor $(\operatorname{tg} \delta)$ is shown in Figure 7 for all the different varieties of nanocomposites. Losses in the nanocomposites do not differ much if compared with the unfilled polymer. Lower values in the whole frequency range were shown by composites with low filler content ( $1 \%$ and $3 \%$ ), while the $10 \%$ specimen always exhibited the highest $\operatorname{tg} \delta$ values. The lower losses can be attributed to a restriction of side chains in proximity of the nanofillers. A broad loss peak at high frequencies (in the $\mathrm{MHz}$ range) is always present and testifies the presence of relaxation phenomena in the polymer.

The dissipation factor takes into account both conduction and polarization losses. In our case, considering the relatively low value of the applied electric field intensity, the increase in electrical resistivity with filler content does not sensibly contribute to a reduction of $\operatorname{tg} \delta$ values with respect to the neat polymer, probably because the effects of deeper trap bands are high-field phenomena. Dissipation factor increases with frequency as shown in Figure 5 since the main contribution is given by polarization losses that are due to molecular friction. The differences at various filler contents are almost negligible.

Also in the $\operatorname{tg} \delta$ spectra we can observe the effects of functionalization which, by stabilizing the adhesion between the filler and the polymer matrix, ensures a more stable behavior of the dissipation factor, with marginal differences among the values measured at different filler content.

\section{Conclusions}

Composite systems based on PBT, containing alumina nanowhiskers, were prepared by batch melt compounding and characterized in terms of morphology and dielectric behavior.

Results have confirmed the importance of filler functionalization and distribution within the hosting matrix [50].

From a dielectric point of view measurements made by now have indicated that 


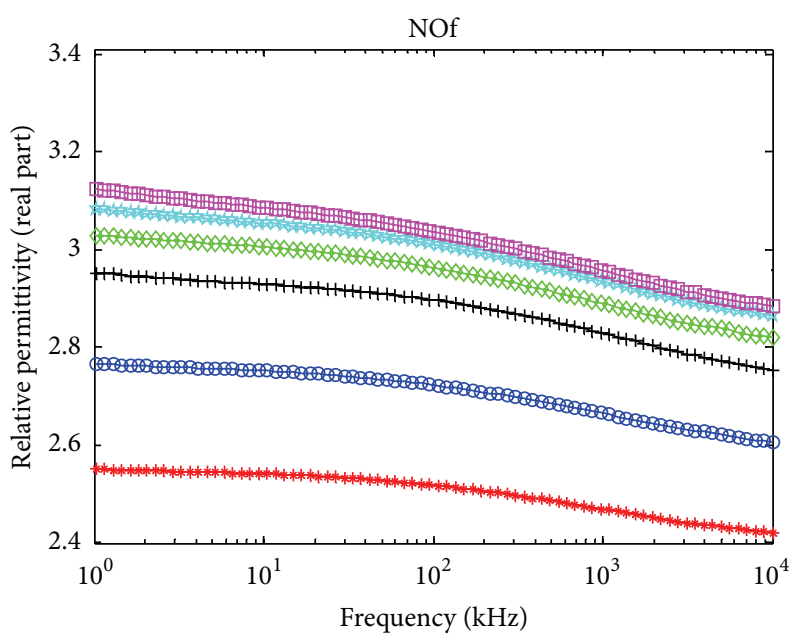

(a)

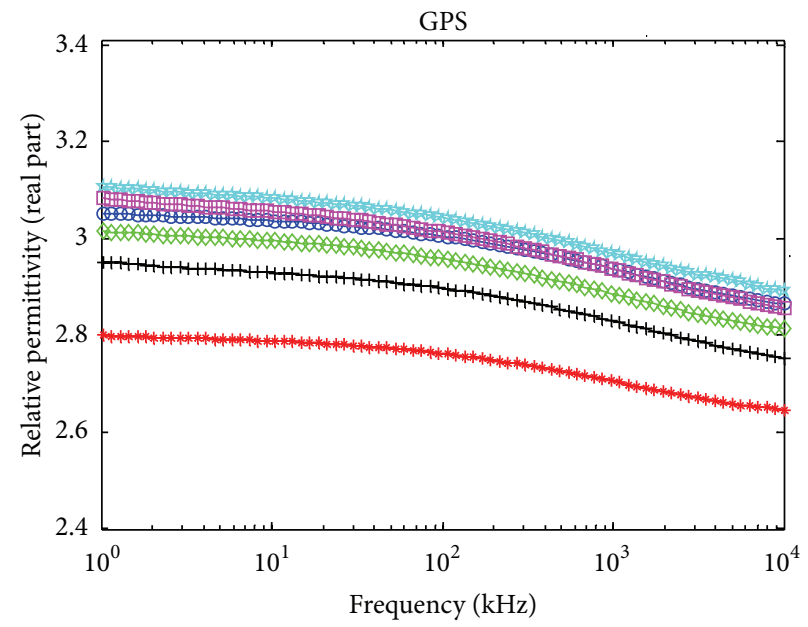

(b)

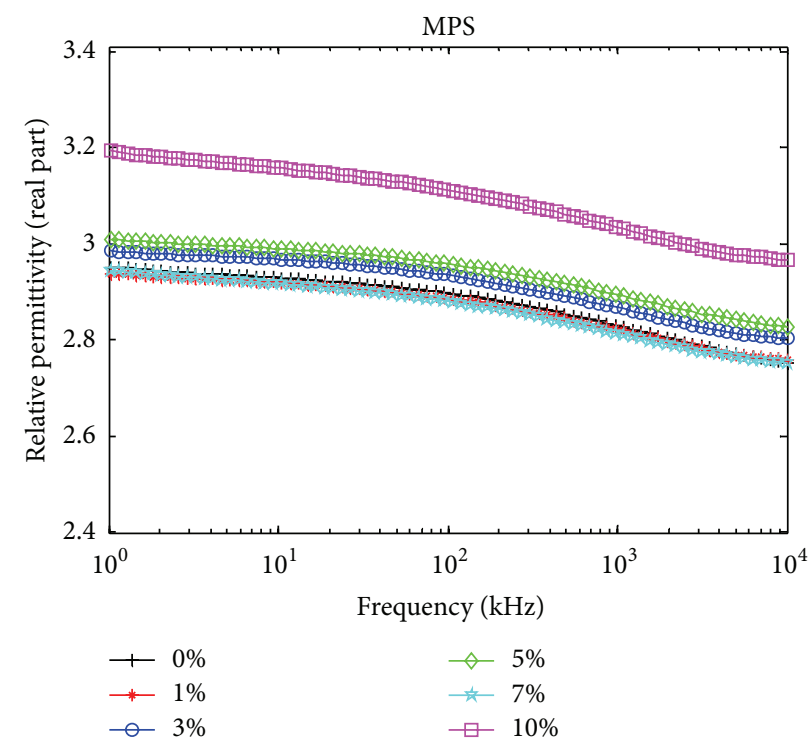

(c)

FIGURE 6: Relative permittivity $(\varepsilon)$ as a function of the applied frequency $(f)$ for systems filled with nonfunctionalized (a), GPS functionalized (b), and MPS functionalized (c) alumina whiskers.

(1) besides the type of filler functionalization the introduction of a small amount of filler induces a relevant increase of the DC resistivity higher than that in nonfunctionalized systems and essentially ascribed to the creation of new trap bands, deeper than the original trap bands of the base polymer; this behaviour fades by increasing the filler content;

(2) dielectric permittivity is reduced with filler contents up to $3 \%$ wt because of usual restrictions of polymer chain movement induced by nanoparticles; it increases at higher filler loadings for the high permittivity of dispersed particles and the onset of interfacial polarization phenomena showing effects ever more pronounced by increasing the applied frequency;
(3) the dissipation factor has minor differences if compared to neat polymer; in any case, it is reduced with respect to the neat matrix for systems with low filler loadings and increases with frequency thus showing a relaxation phenomenon;

(4) functionalization by enhancing the bonding between the nanofillers and the polymer matrix ensures a more stable behavior of the composites as a function of the filler content.

\section{Conflict of Interests}

The authors declare that there is no conflict of interests regarding the publication of this paper. 


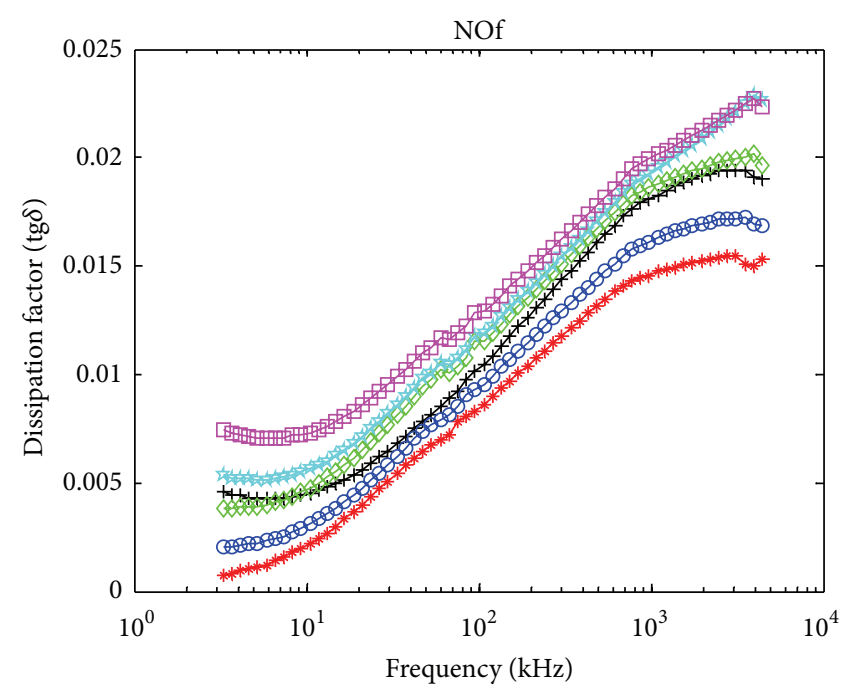

(a)

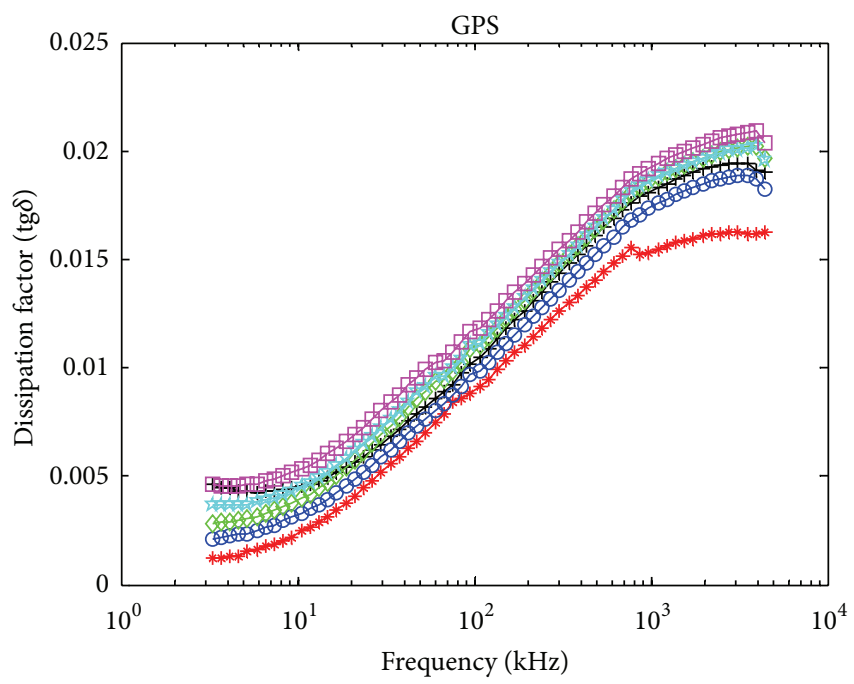

(b)

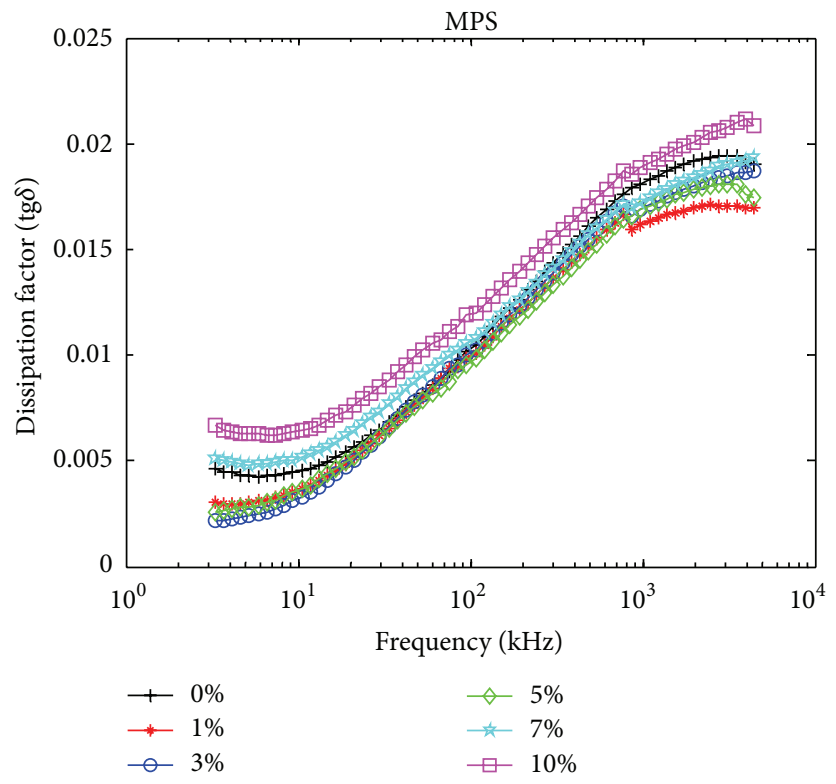

(c)

FIGURE 7: Dissipation factor $(\tan \delta$ ) as a function of the applied frequency $(f)$ for systems filled with nonfunctionalized (a), GPS functionalized (b), and MPS functionalized (c) alumina whiskers.

\section{References}

[1] A. Bigdeli, H. Nazockdast, A. Rashidi, and M. E. Yazdanshenas, "Role of nanoclay in determining microfibrillar morphology development in PP/PBT blend nanocomposite fibers," Journal of Polymer Research, vol. 19, Article ID 9990, 2012.

[2] J. D. Ambrósio and E. Hage Jr., "Effect of processing parameters on the mechanical properties of in situ compatibilized polybutylene terephthalate/acrylonitrile-butadiene-styrene blends," Journal of Applied Polymer Science, vol. 124, no. 4, pp. 27532765, 2012.

[3] I. González, J. I. Eguiazábal, and J. Nazábal, "Characteristics of the brittle/tough transition of poly(butylene terephthalate)/maleinized poly(ethylene-octene) blends determined by the essential work of fracture procedure," Polymer Testing, vol. 29, no. 1, pp. 27-32, 2010.

[4] K. Saeed and S.-Y. Park, "Preparation and properties of polycaprolactone/poly (butylene terephthalate) blend," Iranian Journal of Chemistry and Chemical Engineering, vol. 29, no. 3, pp. 77-81, 2010.

[5] P. Wang, K. Meng, H. Cheng et al., "Reactive compatibilization of polyamide-12/poly(butylene terephthalate) blends with hyperbranched PEI-g-PA12: morphology and thermal properties," Polymer, vol. 50, no. 9, pp. 2154-2160, 2009.

[6] J. Y. Kim, S. W. Kang, and S. H. Kim, "Thermotropic liquid crystal polymer reinforced poly(butylene terephthalate) composites to improve heat distortion temperature and mechanical properties," Fibers and Polymers, vol. 7, no. 4, pp. 358-366, 2006. 
[7] G. S. Deshmukh, D. R. Peshwe, S. U. Pathak, and J. D. Ekhe, "A study on effect of mineral additions on the mechanical, thermal, and structural properties of poly(butylene terephthalate) (PBT) composites," Journal of Polymer Research, vol. 18, no. 5, pp. 10811090, 2011.

[8] D. Wu, L. Wu, and M. Zhang, "Rheology of multi-walled carbon nanotube/poly(butylene terephthalate) composites," Journal of Polymer Science B, vol. 45, no. 16, pp. 2239-2251, 2007.

[9] A. B. Nirukhe and V. V. Shertukde, "Preparation and characterization of poly(butylene terephthalate) Nanocomposites with various organoclays," Journal of Applied Polymer Science, vol. 113, no. 1, pp. 585-592, 2009.

[10] J. Y. Kim, “The effect of carbon nanotube on the physical properties of poly (butylene terephthalate) nanocomposite by simple melt blending," Journal of Applied Polymer Science, vol. 112, no. 5, pp. 2589-2600, 2009.

[11] R. Hajiraissi and M. Parvinzadeh, "Preparation of polybutylene terephthalate/silica nanocomposites by melt compounding: evaluation of surface properties," Applied Surface Science, vol. 257, no. 20, pp. 8443-8450, 2011.

[12] N. Tomar and S. N. Maiti, "Melt rheological properties of PBT/ABAS/MICA composites," Polymer: Plastics Technology and Engineering, vol. 49, no. 6, pp. 617-623, 2010.

[13] B. You, D. Zhou, L. Liu, M. Zen, and X. Ren, "Preparation of HALS-functional core-shell nanoparticles and their application in poly(butylene terephtalate)," Polymer: Plastics Technology and Engineering, vol. 52, no. 9, pp. 946-953, 2013.

[14] E. Gallo, U. Braun, B. Schartel, P. Russo, and D. Acierno, "Halogen-free flame retarded poly(butylene terephthalate) (PBT) using metal oxides/PBT nanocomposites in combination with aluminium phosphinate," Polymer Degradation and Stability, vol. 94, no. 8, pp. 1245-1253, 2009.

[15] E. Gallo, B. Schartel, U. Braun, P. Russo, and D. Acierno, "Fire retardant synergisms between nanometric $\mathrm{Fe}_{2} \mathrm{O}_{3}$ and aluminum phosphinate in poly(butylene terephthalate)," Polymers for Advanced Technologies, vol. 22, no. 12, pp. 2382-2391, 2011.

[16] T. Köppl, S. Brehme, F. Wolff-Fabris, V. Altstädt, B. Schartel, and M. Döring, "Structure-property relationships of halogenfree flame-retarded poly(butylene terephthalate) and glass fiber reinforced PBT,' Journal of Applied Polymer Science, vol. 124, no. 1, pp. 9-18, 2012.

[17] W. Yang, Y. Hu, Q. Tai, H. Lu, L. Song, and R. K. K. Yuen, "Fire and mechanical performance of nanoclay reinforced glassfiber/PBT composites containing aluminum hypophosphite particles," Composites A: Applied Science and Manufacturing, vol. 42, no. 7, pp. 794-800, 2011.

[18] L. Vereb, P. Osmokrovic, M. Vujisic, C. Dolicanin, and K. Stankovic, "Prospects of constructing $20 \mathrm{kV}$ asynchronous motors," IEEE Transactions on Dielectrics and Electrical Insulation, vol. 16, no. 1, pp. 251-256, 2009.

[19] C. Petrarca, A. Maffucci, V. Tucci, and M. Vitelli, "Analysis of the voltage distribution in a motor stator winding subjected to steep-fronted surge voltages by means of a multiconductor lossy transmission line model," IEEE Transactions on Energy Conversion, vol. 19, no. 1, pp. 7-17, 2004.

[20] B. De Vivo, P. Lamberti, V. Tucci, and C. Petrarca, "Simulation of the bearing voltage in an inverter-fed induction motor by a full three phase multi conductor transmission line model," Progress in Electromagnetics Research B, vol. 46, pp. 233-250, 2013.
[21] Z.-M. Dang, Y.-F. Yu, H.-P. Xu, and J. Bai, "Study on microstructure and dielectric property of the $\mathrm{BaTiO}_{3}$ /epoxy resin composites," Composites Science and Technology, vol. 68, no. 1, pp. 171177, 2008.

[22] J. Yu, R. Huo, C. Wu, X. Wu, G. Wang, and P. Jiang, "Influence of interface structure on dielectric properties of epoxy/alumina nanocomposites," Macromolecular Research, vol. 20, pp. 816826, 2012.

[23] H. Zhao and R. K. Y. Li, "Effect of water absorption on the mechanical and dielectric properties of nano-alumina filled epoxy nanocomposites," Composites A: Applied Science and Manufacturing, vol. 39, no. 4, pp. 602-611, 2008.

[24] Q. Wang and G. Chen, "Effect of nanofillers on the dielectric properties of epoxy nanocomposites," Advanced Materials Research, vol. 1, pp. 93-107, 2012.

[25] E. Amendola, A. M. Scamardella, C. Petrarca, and D. Acierno, "Epoxy-nanocomposites with ceramic reinforcement for electrical insulation," Journal of Applied Polymer Science, vol. 122, no. 6, pp. 3686-3693, 2011.

[26] A. M. Scamardella, E. Amendola, C. Petrarca, and D. Acierno, "Thermo-mechanical and electrical properties of epoxy composites containing ceramic nanofillers," in Proceedings of the 5th International Conference on Times of Polymers (TOP) and Composites, pp. 206-208, Ischia, Italy, June 2010.

[27] I. Ramirez, E. A. Cherney, S. Jayaram, and M. Gauthier, “Thermogravimetric and spectroscopy analyses of silicone nanocomposites," in Proceedings of the Annual Report Conference on Electrical Insulation and Dielectric Phenomena (CEIDP '08), pp. 249-252, Quebec City, Canada, 2008.

[28] E. Amendola, G. Lupò, C. Petrarca, and A. M. Scamardella, "Alumina filled silicone nanocomposites for electrical insulation of power rotating machines," International Journal of Applied Electromagnetics and Mechanics, vol. 39, no. 1-4, pp. 3$11,2012$.

[29] V. Tomer, G. Polizos, C. A. Randall, and E. Manias, "Polyethylene nanocomposite dielectrics: implications of nanofiller orientation on high field properties and energy storage," Journal of Applied Physics, vol. 109, no. 7, Article ID 074113, 2011.

[30] J. I. Hong, P. Winberg, L. S. Schadler, and R. W. Siegel, "Dielectric properties of zinc oxide/low density polyethylene nanocomposites," Materials Letters, vol. 59, no. 4, pp. 473-476, 2005.

[31] N. J. S. Sohi, M. Rahaman, and D. Khastgir, "Dielectric property and electromagnetic interference shielding effectiveness of ethylene vinyl acetate-based conductive composites: effect of different type of carbon fillers," Polymer Composites, vol. 32, no. 7, pp. 1148-1154, 2011.

[32] D. Fabiani, G. C. Montanari, and F. Palmieri, "Effect of nanoparticle size on space charge behavior of $\mathrm{EVA} / \mathrm{TiO}_{2}$ nanocomposites," in Proceedings of the Annual Report Conference on Electrical Insulation and Dielectric Phenomena (CEIDP '11), pp. 322-325, 2011.

[33] C.-W. Tang, B. Li, L. Sun, B. Lively, and W.-H. Zhong, "The effects of nanofillers, stretching and recrystallization on microstructure, phase transformation and dielectric properties in PVDF nanocomposites," European Polymer Journal, vol. 48, pp. 1062-1072, 2012.

[34] P. Khodaparast and Z. Ounaies, "On the impact of functionalization and thermal treatment on dielectric behavior of low content $\mathrm{TiO}_{2}$ PVDF nanocomposites," IEEE Transactions on Dielectrics and Electrical Insulation, vol. 20, pp. 166-167, 2013. 
[35] F. He, S. Lau, H. L. Chan, and J. Fan, "High dielectric permittivity and low percolation threshold in nanocomposites based on poly(vinylidene fluoride) and exfoliated graphite nanoplates," Advanced Materials, vol. 21, no. 6, pp. 710-715, 2009.

[36] M. Ieda, "Carrier injection, space charge and electrical breakdown in insulating polymers," IEEE Transactions on Electrical Insulation, vol. 22, no. 3, pp. 261-267, 1987.

[37] T. Mizutani, "Space charge measurement techniques and space charge in polyethylene," IEEE Transactions on Dielectrics and Electrical Insulation, vol. 1, no. 5, pp. 923-933, 1994.

[38] J. K. Nelson, J. C. Fothergill, L. A. Dissado, and W. Peasgood, "Towards an understanding of nanometric dielectrics," in Proceedings of the IEEE Conference on Electrical Insulation and Dielectric Phenomena, pp. 295-298, October 2002.

[39] R. C. Smith, C. Liang, M. Landry, J. K. Nelson, and L. S. Schadler, "The mechanisms leading to the useful electrical properties of polymer nanodielectrics," IEEE Transactions on Dielectrics and Electrical Insulation, vol. 15, no. 1, pp. 187-196, 2008.

[40] G. C. Montanari, D. Fabiani, F. Palmieri, D. Kaempfer, R. Thomann, and R. Mülhaupt, "Modification of electrical properties and performance of EVA and PP insulation through nanostructure by organophilic silicates," IEEE Transactions on Dielectrics and Electrical Insulation, vol. 11, no. 5, pp. 754-762, 2004.

[41] T. Tanaka, G. C. Montanari, and R. Mülhaupt, "Polymer nanocomposites as dielectrics and electrical insulationperspectives for processing technologies, material characterization and future applications," IEEE Transactions on Dielectrics and Electrical Insulation, vol. 11, no. 5, pp. 763-784, 2004.

[42] D. K. Shukla and R. K. Srivastava, "Effect of alumina platelet reinforcement on dynamic mechanical properties of epoxy," in Proceedings of the World Congress on Engineering (WCE '11), pp. 1930-1934, London, UK, July 2011.

[43] Z. Guo, T. Pereira, O. Choi, Y. Wang, and H. T. Hahn, "Surface functionalized alumina nanoparticle filled polymeric nanocomposites with enhanced mechanical properties," Journal of Materials Chemistry, vol. 16, no. 27, pp. 2800-2808, 2006.

[44] S. Singha and M. J. Thomas, "Dielectric properties of epoxy$\mathrm{Al}_{2} \mathrm{O}_{3}$ nanocomposite system for packaging applications," IEEE Transactions on Components and Packaging Technologies, vol. 33, no. 2, pp. 373-385, 2010.

[45] M. Takala, Electrical Insulation Materials towards Nanodielectrics [Ph.D. thesis], Tampere University of Technology.

[46] R. Kochetov, T. Andritsch, P. H. F. Morshuis, and J. J. Smit, "Anomalous behaviour of the dielectric spectroscopy response of nanocomposites," IEEE Transactions on Dielectrics and Electrical Insulation, vol. 19, no. 1, pp. 107-117, 2012.

[47] T. Tanaka, "Dielectric nanocomposites with insulating properties," IEEE Transactions on Dielectrics and Electrical Insulation, vol. 12, no. 5, pp. 914-928, 2005.

[48] E. David and M. Frèchette, "Polymer nanocomposites-major conclusions and achievements reached so far," IEEE Electrical Insulation Magazine, vol. 29, no. 6, pp. 29-36, 2013.

[49] T. Tanaka, Y. Ohki, M. Ochi, M. Harada, and T. Imai, "Enhanced partial discharge resistance of epoxy/clay nanocomposite prepared by newly developed organic modification and solubilization methods," IEEE Transactions on Dielectrics and Electrical Insulation, vol. 15, no. 1, pp. 81-89, 2008.

[50] D. Tan, Y. Cao, E. Tuncer, and P. Irwin, "Nanofiller dispersion in polymer dielectrics," Materials Sciences and Applications, vol. 4, no. 4, pp. 6-15, 2013. 

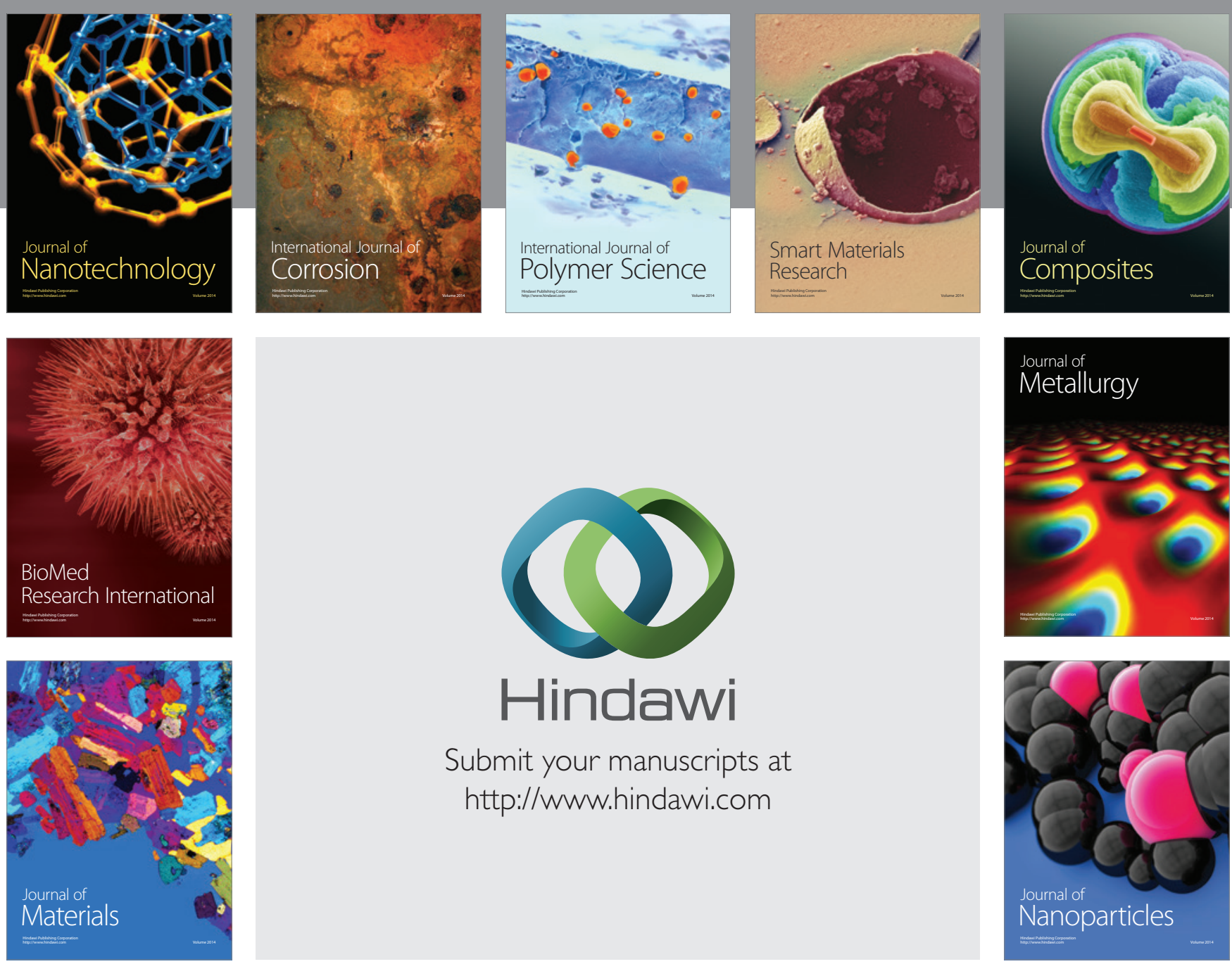

Submit your manuscripts at http://www.hindawi.com
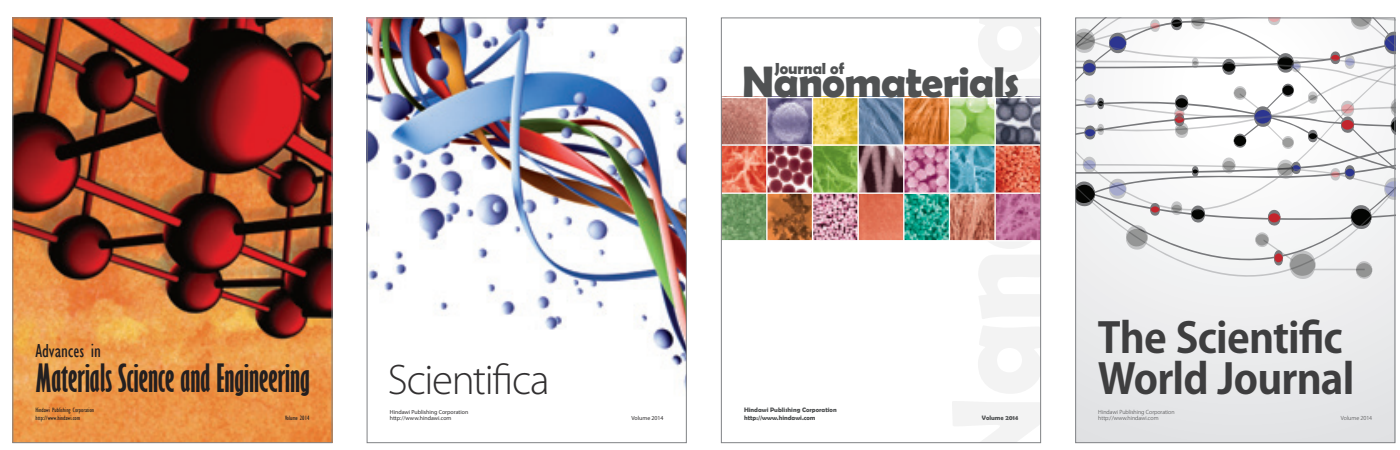

\section{The Scientific World Journal}
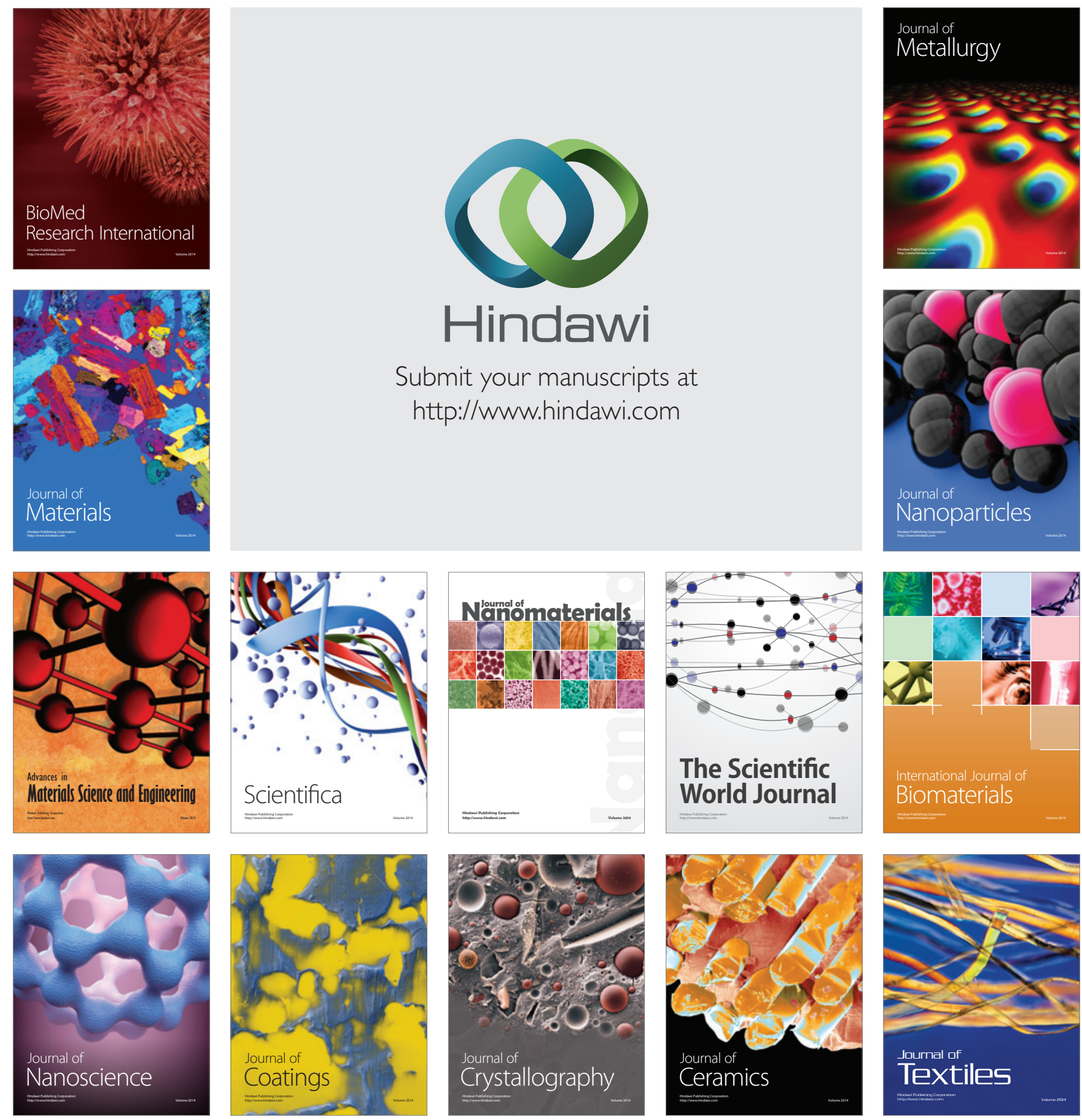